\title{
Dossiê
}

\section{A TRAMA CIENTÍFICA E JURÍDICA NA CONSTRUÇÃO DO CERTIFICADO DE AGROFLORESTAS}

\author{
Matheus Sehn Korting \\ Mestre em Desenvolvimento Rural pelo PGDR-UFRGS
}

\begin{abstract}
RESUMO
Este artigo tem como propósito desenvolver a trama científica e jurídica formada em torno do Certificado de Agroflorestas. Será demonstrando as origens do termo Agroflorestas e a transformação do conceito por instituições científicas. Também será demonstrado o aparato jurídico que subsidia as políticas ambientais desde a Constituição Federal e seus princípios à legislações infraconstitucionais em direção aos licenciamentos florestais. Nos licenciamentos florestais, a ideia é a de analisar a formação do certificado pelos técnicos como instrumento de disciplina apto a incluir a multiplicidade das práticas de Agroflorestas.
\end{abstract}

Palavras-chave: Certificado de Agroflorestas; Licenciamentos florestais; Políticas ambientais.

\begin{abstract}
This article aims to develop the scientific and legal frame formed around the Agroforestry Certificate. It will be demonstrating the origins of Agroforestry term and the transformation of the concept by the institutions. It will also be shown the legal apparatus that supports environmental policies since the Federal Constitution and its principles to infra legislation towards the forest licensing. In forest licenses, the idea is to analyze the formation of the certificate as a discipline tool able to include the multiplicity of Agroforestry practices.
\end{abstract}

Key words: Agroforestry Certificate; Forest licenses; Environmental policies. 


\section{INTRODUÇÃO}

O presente artigo parte de inquietações surgidas após os estudos realizados sobre certificação em Agroflorestas e legislação florestal, direcionadas à relação sociedade-natureza e a produção de saber científico sobre a multiplicidade de práticas de agricultores relativas às Agroflorestas.

O objetivo é o de mapear a trama entre as ciências agronômicas e biológicas para o processo de formatação jurídica do Certificado de Agroflorestas proposto por atores de instituições ambientais e de extensão rural, de instituições de ensino, de movimentos sociais, fomentada por discussões dentro de espaços políticos e acadêmicos no Rio Grande do Sul. A intenção desses atores era a de reverter uma situação de ilegalidade de usos, corte e podas de árvores nativas - amparadas pelo artigo $6^{\circ}$ do Código Florestal Gaúcho - frente a usos de técnicas tradicionais para a manutenção de sistemas produtivos onde florestas e cultivos agrícolas são intencionalmente cultivados juntos (NAIR, 1973).

Dentro de um contexto possibilitado pelo "Projeto Fortalecimento das Agroflorestas no Rio Grande do Sul: Etnoecologia, Formação de Rede e Segurança Alimentar e Nutricional", financiado pelo Ministério do Desenvolvimento Agrário (MDA) e o Conselho Nacional de Desenvolvimento Científico e Tecnológico ( $\mathrm{CNPq}$ ), e executado em conjunto pela Universidade Federal do Rio Grande do Sul (UFRGS) e pela Empresa de Assistência em Extensão Rural (EMATER/RS), o que se notou foi que os agricultores utilizavam técnicas agroflorestais com uma grande diversidade de espécies e árvores nativas, mas eram barrados e restringidos pelas legislações ambientais, guardadas as peculiaridades regionais.

Nesse contexto, com a intenção de promover as Agroflorestas, uma trama científica foi desenvolvida tanto nos espaços acadêmicos quanto institucionais permeada por argumentos de proteção ambiental e de produção de alimentos saudáveis, negociando e reinvindicando espaços dentro dos regramentos para o incentivo de práticas agroflorestais com um cunho agroecológico. $\mathrm{O}$ reconhecimento de uma demanda latente por novas formas de cultivo agroecológicos e de incentivo à biodiversidade tornaram-se objeto de interesse de instituições governamentais, como órgãos de pesquisa, órgãos de fiscalização e proteção ambiental e de extensão rural. Ao mesmo tempo, agricultores esperavam ver facilitadas as condições para o manejo, o corte e a comercialização de árvores e frutos nativos. 


\section{A trama científica e jurídica na construção do certificado de agroflorestas}

Após participar de diversas reuniões, acessar documentações, legislações, conhecer diversas propriedades rurais com agroflorestas e realizar uma série de entrevistas, uma das possibilidades de negociação que chancelou o certificado de Agroflorestas é a de que pequenos produtores iriam poder, através de um certificado expedido pelos órgãos ambientais competentes, legalizar suas agroflorestas pautadas por diversas legislações, tanto de âmbito nacional quanto estadual. Tal fato foi possível através de uma arena de conhecimentos com o desafio de apresentar elementos e atributos mínimos capazes de atender aos interesses da preservação ambiental e da alimentação saudável em um certificado de acordo com os regramentos jurídicos dispostos na legislação ambiental. A missão dessa arena era enquadrar a multiplicidade de práticas dos agricultores em um formato jurídico capaz de atender ao regramento vigente.

No presente artigo, proponho inicialmente a pensar a formação do conceito das Agroflorestas na história, através de um histórico nos quais circulam conceitos, instituições e diferentes contextos onde o termo foi fixado. Na sequência pretendo demonstrar a atualidade das Agroflorestas dentro da atual legislação ambiental brasileira, tanto pela Constituição Federal de 1988 quanto por diferentes dispositivos da seara ambiental, pensando os regramentos como um sistema lógico de regramentos e que, além de garantias à proteção ambiental, possui instrumentos de fomento à produção sustentável, de povos tradicionais, de produção agroflorestal.

O último espaço a ser desenvolvido versa sobre a formação do certificado de Agroflorestas no Rio Grande do Sul para os agricultores se regularizarem e a forma que dialogam conceitos e práticas de Agroflorestas, legislações ambientais e, principalmente, como é pensada a trama científica e jurídica, a que(m) se destina, tendo em vista a multiplicidade de práticas dos agricultores.

\section{AS AGROFLORESTAS NA HISTÓRIA}

Mesmo que os saberes em torno das Agroflorestas se proponham como ferramentas alternativas e tenham um grau de positividade inerente, aqui a ideia é suspender uma adesão espontânea ao conceito de Agroflorestas e historicizá-la, pensá-lo em sua história no mundo e em seus contextos de criação, colocando sob suspeita os saberes produzidos no ramo acadêmico/científico. É pensar que o conceito de Agroflorestas está em disputa transportando ideais de atores diversos desde sua origem até os dias atuais. O que está em jogo é historicizar a pretensão ao domínio exclusivo de uma verdade havendo um espaço de uma multiplicidade de visões em combate (ANJOS, 2004). 
NORUS - v3, n.4, jul - dez 2015.

As Agroflorestas emergem como um discurso oficial na década de 70 como parte integrante do cenário da Revolução Verde e da modernização agrícola. O discurso de Robert McNamara, presidente do Banco Mundial na época, aponta a importância do milagre da Revolução Verde e lamenta a pobreza rural e os contínuos desmatamentos em países de terceiro mundo.

\begin{abstract}
"Dos dois bilhões de pessoas que vivem em nossos países em desenvolvimento, cerca de dois terços, ou algo em torno de 1,3 bilhões de pessoas, são membros de famílias de agricultores, e dentre estes cerca de 900 milhões possuem rendimentos anuais em média inferior a 100 dólares [...] Para centenas de milhões desses agricultores de subsistência a vida não é nem satisfatória, nem decente. A fome e a desnutrição ameaçam suas famílias. Analfabetismo exclui os seus futuros. A doença e a morte visitam suas aldeias [...] $\mathrm{O}$ milagre da Revolução Verde chegou, mas, na maioria das vezes, o agricultor pobre não tem conseguido participar. Ele não pode se dar ao luxo de pagar para a irrigação, o pesticida, o fertilizante, ou talvez para a própria terra, em que o título pode ser vulnerável e seu arrendamento incerto." (KING, 1987, p. 6, tradução nossa).
\end{abstract}

É nesse léxico entre Revolução Verde, fome, pobreza e florestas que começa a nascer pesquisas, incentivos e a possibilidade de que as florestas possam ser um espaço também de produção de alimentos. Neste contexto, a ideia de Robert McNamara, presidente do Banco Central em 1973, era a de promover políticas florestais diferenciadas das que a "indústria florestal" da silvicultura vinha fazendo nos países em desenvolvimento - em especial sobre as florestas tropicais - e políticas diferenciadas da agricultura moderna proporcionada pelos "milagres" produzidos pela Revolução Verde, para pensar na pobreza rural, na fome e na degradação ambiental.

É importante aqui salientar o espaço do discurso desenvolvimentista que apostou na renovação da Revolução Verde através de novas técnicas, como a Agrofloresta. Estudos como os de Graziano da Silva (1996) e George Martine (1991) apontam que a adesão à pacotes tecnológicos provenientes da Revolução Verde foram (e ainda hoje são) causadoras de impactos ambientais, sociais e econômicos através da reformulação do capital e trabalho no meio rural, da concessão de créditos agrícolas direcionados a espaços mais produtivos e, principalmente, ao acesso restrito à modernização mecânica e biotecnológica.

Dos estudos apresentados na época, sugeriam-se "evitar a falsa dicotomia entre agricultura e silvicultura" (KING, 1987) através de uma interface entre agricultura e silvicultura para suprir as necessidades de produzir comida e madeira através da integração de técnicas, a agrossilvicultura. $\mathrm{O}$ que estava se sugerindo era uma interface entre a produção agrícola e a florestal, através da não devastação das florestas nos países tropicais de modo a não exaurir recursos florestais, agrícolas, econômicos e culturais.

O termo Agrofloresta foi pela primeira vez pronunciado publicamente através do livro "Trees, food and people" (BENE, BEAL, COTÊ, 1977) preocupados em fornecer o conceito de um sistema de uso da terra capaz de fornecer alimentos e madeira enquanto ao mesmo tempo conserva 


\section{A trama científica e jurídica na construção do certificado de agroflorestas}

e reabilita ecossistemas. Em 1987, foi publicado um livro "Agroforestry: A decade of development" financiado pelo ICRAF - International Council for Research in Agroforestry - onde uma série de cientistas à época a frente nos estudos conta a recente história do desenvolvimento das Agroflorestas.

Uma nova frente pode e deve ser aberta na guerra contra a fome, abrigo inadequado e degradação ambiental. Esta guerra pode ser travada com armas que existem no arsenal das populações rurais desde tempos imemoriais, e nenhuma mudança radical em seu estilo de vida é necessária (KING, 1987, p. 8, tradução nossa)

A prática de cultivar árvores e espécies agrícolas em combinação é, de fato, uma prática muito antiga. Remonta a um tempo onde esses conceitos, essas práticas e as certificações oriundas do conceito de Agroflorestas não fariam o menor sentido. King (1987) ao apresentar essas práticas antigas afirma que eram comum na Europa, até a Idade Média ao menos, clareiras sendo abertas nas florestas para realizar plantações em sistema de rodízio. Nas Filipinas, os Hanunóó praticavam agricultura itinerante através de uma complexa seleção de sementes a serem plantadas em diferentes períodos do ano.

$\mathrm{Na}$ América, alguns povos tradicionais imitavam a estrutura da floresta para a agricultura ser beneficiada através de diferentes espécies em estratos e camadas diferentes como um estrato com coco e uma camada inferior com citrus e bananeira e um estrato arbustivo com café, realizando um misto de várias plantas imitando a configuração da floresta tropical. Assim como no sul da Nigéria o plantio de inhame, milho, abóbora e feijão sob a cobertura de árvores dispersas num sistema intensivo de misturas de herbáceas, arbustos e árvores, que se propunha a manter a fertilidade do solo, combater a erosão e lixiviação de nutrientes.

Segundo King (1987) essas práticas já foram denominadas de muitas formas em diferentes espaços, onde em alemão era chamado de baumfeldwirtschaft, brandwirtschaft, ou waldfeldbau, em francês era cultures sylvicole e agricole combinee, culture intercalates, la mithode sylvo agricole, la systime syho-bananier e plantation sur culture. Em holandês o nome era Bosakkerbouw. Em Porto Rico era chamado de sistema de parcelero, no Brasil era consorciação. O nome na Libya era tahmil, nas Filipinas era kaingining, em Malaya era ladang, em Kenya era o sistema shamba, em Sri Lanka era chena, na India foi descrito como dhya, jhooming, kumri, Punam, taila e tuckle. Em outros países do mundo também era chamado de taungya. Essas práticas que vieram a culminar no nome agrossilvicultura e depois o termo Agroflorestas, onde as árvores eram parte integrante do sistema de agricultura cujo objetivo final não era a produção de árvores, mas a produção de alimentos (KING, 1987).

Notadamente essas primeiras conceituações sobre Agroflorestas partiram de centros 
NORUS - v3, n.4, jul - dez 2015.

acadêmicos como o ICRAF que iniciaram seus trabalhos pela década de 70 e ainda hoje possuem seus estudos científicos na temática. Em 2002, o ICRAF tornou-se o World Agroforestry Centre e seus trabalhos atingem uma escala global em países em desenvolvimento principalmente países da América do Sul, da Ásia e da África. Atualmente suas ações políticas são financiadas por governos de diferentes países, investimentos privados, organizações internacionais e de bancos junto a CGIAR - Consultative Group on International Agricultural Researche - e o Banco Mundial preocupados em ações de redução da pobreza, combate a fome e segurança alimentar.

Então outros grupos começam a despontar nas pesquisas sobre Agroflorestas fomentando outras discussões ainda não pensada pelo grupo ICRAF. Um desses grupos é o CATIE (Centro Agronómico Tropical de Investigación y Enseñanza) da Costa Rica e a ACASOC (Associacion del Colectivo de Agroecología del Suroccidente Colombiano) da Colombia.

$\mathrm{Na}$ década de 1990, Eduardo Somarriba do CATIE lança o artigo "O que es agroforesteria" na tentativa de acrescentar à agroforesteria discussões que assombravam o conceito na época. Sob a alegação de que "qualquer coisa pode ser agrofloresta" pelo fato de que os conceitos vigentes eram demasiado amplos, as Agroflorestas seguiam por um expansionismo acrítico (SOMARRIBA, 1990). As principais contribuições de Somarriba são sobre alguns limites que propõe para o conceito. Propõe que os antigos conceitos acabavam incorporando práticas de monocultivos e propunha cultivos múltiplos, que usavam termos imprecisos como o de interações biológicas "significativas", propondo que para ser uma Agrofloresta essas interações deveriam ser mais precisas ou não seria uma Agrofloresta e que a simples coleta de frutos não constituiria uma Agrofloresta, por não haver nem manejo intencionado nem cultivo de espécies.

Já a ACASOC, com um cunho forte voltada para a Agroecologia e também tentando repensar a corrente majoritária sobre os Sistemas Agroflorestais formados, propõe-se a pensar tendo em vista seus espaços de pesquisa, as florestas tropicais. Alfredo Ospina (2006) argumenta que as Agroflorestas possuem uma conexão muito forte com os ideários da Agroecologia e baseia-se em uma visão interdisciplinar onde a Agroforesteria - como é chamado em espanhol - dá uma resposta as limitações teóricas e instrumentais herdadas pela ciência moderna provenientes da Revolução Verde para três de suas disciplinas, a agronomia, a silvicultura e a zootecnia. Alfredo Ospina afirma que existem modalidades de agroforesterias convencionais que reproduziriam o mesmo disciplinamento cientificizante da Revolução Verde através do difusionismo e transferência tecnológica considerando o agricultor como mero receptor da ciência agronômica.

Aos "homens de ciência" (COSTA GOMES; ROSENSTEIN, 2000), a crença histórica do cientificismo dirigido por códigos de racionalidade que fundam uma relação de dominação na 


\title{
A trama científica e jurídica na construção do certificado de agroflorestas
}

produção e na difusão do conhecimento. O conhecimento é descoberto por um e para a mera aplicação do outro. Ao "um", o pensar sobre Ciência e Tecnologia. Ao "outro", receber o conhecimento já preestabelecido. Nesse sentido, conhecimentos de agroforesterias convencionais estão em posse de elites científicas e educativas negando os saberes tradicionais locais através de um conhecimento reproduzido por fora das localidades e regiões com metodologias transplantadas das disciplinas convencionais.

Ao mesmo tempo Ospina propõe, em especial para as florestas tropicais, que a real agroforesteria é uma interdisciplina ${ }^{1}$, uma tradição e inovação produtiva e de conservação da natureza desenvolvida por culturas agroflorestais já realizadas por povos tradicionais e que a luta é a de manter esse ideário de uma produção biodiversa, livre de agrotóxicos, aproveitamento de recursos locais com interações ecológicas de complementariedade do sistema.

\begin{abstract}
A agrofloresta é [...] desenvolvida principalmente por culturas agroflorestais em terras tropicais, onde existem formas de manejo e aproveitamento de sistemas agroflorestais em fazendas e terras comunitárias para a produção de biodiversidade, livre de agrotóxicos e duradoura com predomínio e desenvolvimento do conhecimento tradicional e inovador, o fortalecimento da identidade cultural, as interações ecológicas totais do sistema de complementaridade, a diversificação da paisagem, a utilização adequada dos recursos naturais, o privilégio do trabalho humano, o uso de tecnologias de baixo impacto ambiental de agrotóxicos e duradoura relações e bem-estar social e econômico, equidade e justiça. (OSPINA, 2006, p. 22, tradução nossa)
\end{abstract}

O que importa relacionar nesse tópico é que diferentes esforços são realizados em torno da proposta das Agroflorestas, todos derivados de espaços científicos, disputando em torno da formação desse conceito que é chave para o trabalho. As Agroflorestas vêm tomando diferentes interpretações e estão entre modelos de transferência de tecnologia top-down e uma prática interdisciplinar mais justa, com participação dos agricultores.

Libertar o leitor de uma adoção espontânea às Agroflorestas é importante para descrever que assim como não há um consenso sobre o conceito científico de Agroflorestas - tendo em vista que existem diferentes visões sobre o objeto - não há também uma uniformidade nas práticas dos agricultores que cultivam árvores e cultivos agrícolas.

1 Sobre a interdisciplina, Ospina constrói que "a construção e/ou reconstrução do saber e conhecimento agroflorestal, de acordo com a complexidade ecossistêmica e cultural do trópico passa pela interdisciplinariedade, como resposta as limitações teóricas e instrumentais herdadas das ciências modernas (agronomia, silvicultura e zootecnia convencionais ou da Revolução Verde). A interdisciplinariedade deve permitir integrar e compreender de maneira holística aspectos socioeconômicos e biotécnicos do âmbito agroflorestal, que não deu até agora resposta." (OSPINA, 2006, p. 47) Além disso, importante frisar que a interdisciplina aqui proposta como metodologia do conceito de Agrofloresta não tem relação com os dispositivos disciplinares que Michel Foucault (1999) propõe. Ainda que essa relação possa existir, aqui o termo interdisciplina é tomado no seu sentido literal. 
NORUS - v3, n.4, jul - dez 2015.

“ORDEM NO MATO": DA NORMA CONSTITUCIONAL AOS LICENCIAMENTOS

FLORESTAIS

Antes de chegarmos ao certificado de Agroflorestas será feito um resgate do ordenamento jurídico para compreendermos a que rede de normas esse certificado está vinculado. Do nível mais geral de produção de normas jurídicas até o nível de execução das normas jurídicas (BOBBIO, 1995), temos a Constituição Federal como maior produtor de normas jurídicas sendo base de direitos e garantias fundamentais, para em seguida leis complementares executarem a Constituição, tais como o Código Florestal, a Lei da Mata Atlântica.

Por fazer parte de normativas e políticas ambientais do Estado, os licenciamentos florestais vinculam-se tanto a normativas estaduais quanto as normativas nacionais, em especial a Constituição Federal, fazendo parte das políticas em torno do direito ao meio ambiente ecologicamente equilibrado. Para assegurar as garantias produzidas pela Constituição, os licenciamentos florestais são instrumentos para a execução dessas produções e o certificado de Agroflorestas é um desses.

Presente em nossa Constituição Federal de 1988, o direito ao meio ambiente ecologicamente equilibrado é um direito fundamental conquistado pela sociedade civil e pelo Estado. São direitos fundamentais aqueles que, formalmente, são reconhecidos na Constituição ou em tratados internacionais, atribuindo a indivíduos ou a grupos de indivíduos uma garantia subjetiva ou pessoal. Tratando-se do direito fundamental ao meio ambiente ecologicamente equilibrado, tem-se aqui um direito que possui como beneficiários a sociedade, as gerações futuras, os seres vivos e os processos ecológicos (BENJAMIM, 2010).

$\mathrm{O}$ artigo constitucional garante do direito ao meio ambiente equilibrado é o art. 225

Art. 225 - Todos têm direito ao meio ambiente ecologicamente equilibrado, bem de uso comum do povo e essencial à sadia qualidade de vida, impondo-se ao Poder Público e à coletividade o dever de defendê-lo e preservá-lo para as presentes e futuras gerações.

$\S 1^{\circ}$ - Para assegurar a efetividade desse direito, incumbe ao Poder Público:

I - preservar e restaurar os processos ecológicos essenciais e prover o manejo ecológico das espécies e ecossistemas;

$[\ldots]$

III - definir, em todas as unidades da Federação, espaços territoriais e seus componentes a serem especialmente protegidos, sendo a alteração e a supressão permitidas somente através de lei, vedada qualquer utilização que comprometa a integridade dos atributos que justifiquem sua proteção;

VII - proteger a fauna e a flora, vedadas, na forma da lei, as práticas que coloquem em risco sua função ecológica, provoquem a extinção de espécies ou submetam os animais a crueldade.

[...]

$\S 4^{\circ}$ - A Floresta Amazônica brasileira, a Mata Atlântica, a Serra do Mar, o Pantanal Mato- 


\section{A trama científica e jurídica na construção do certificado de agroflorestas}

Grossense e a Zona Costeira são patrimônio nacional, e sua utilização far-se-á, na forma da lei, dentro de condições que assegurem a preservação do meio ambiente, inclusive quanto ao uso dos recursos naturais. (BRASIL, 1988).

Esse artigo constitucional é uma síntese dos dispositivos ambientais (FELDMAN; CAMINO, 1992) ligando-se a proteção à vida e à saúde, a dignidade da pessoa humana e a função socioecológica da propriedade, também garantidos - como direito fundamental - na Constituição. Nesse artigo é que se incumbe ao Poder Público a preservação, a proteção e a restauração de processos ecológicos, da flora e da fauna e o provimento de manejo ecológico de espécies e ecossistemas. Além disso, a definição de espaços a serem protegidos, considerando a Floresta Amazônica brasileira, a Mata Atlântica, a Serra do Mar, o Pantanal Mato-Grossense e a Zona Costeira como patrimônios nacionais a serem preservados.

Sobre os princípios constitucionais que norteiam a temática ambiental, além dos escritos na Constituição e os direitos fundamentais que funcionam como princípios (ALEXY, 1993), os princípios de direito ambiental são o princípio da primariedade do meio ambiente, o princípio da explorabilidade limitada da propriedade (e dos recursos naturais), o princípio do uso sustentável dos recursos naturais, o princípio da prevenção, o princípio da precaução, o princípio poluidor-pagador e o princípio da função ecológica da propriedade.

A constitucionalização do ambiente e ecologização da Constituição, como chamou Benjamim (2010), traz um elencar de técnicas constitucionais importantes para a efetivação do direito ao meio ambiente equilibrado. Contraposto ao direito de explorar e do direito de propriedade, o dever constitucional de não degradar o ambiente substitui a explorabilidade plena e incondicionada para uma explorabilidade limitada e condicionada tendo em vista que qualquer exploração econômica de recursos naturais necessita da observância de limites e condições presente na lei, através da legitimação constitucional da função estatal reguladora.

A explorabilidade limitada e condicionada traz para o direito ao meio ambiente equilibrado uma estrutura bifronte: um direito negativo associada ao direito de non facere; e positiva associada as prestações positivas do Estado e da sociedade tanto no que tange as políticas como para as licenças a serem concedidas (BENJAMIM, 2010).

A constitucionalização do ambiente traz como benefício a segurança normativa sendo considerada norma pétrea que traz estabilidade e é anteparo ao exercício discricionário da autoridade (BONAVIDES, 1994) havendo obrigatoriedade no cumprimento das normas, marco importante que modificou o paradigma de leis esparsas a serem cumpridas antes de 1988. A ecologização da Constituição nos institui um regime de exploração limitada e condicionada da propriedade e agregar à função social da propriedade um componente ambiental (BENJAMIM, 
NORUS - v3, n.4, jul - dez 2015.

2010).

Após passar pelas normas constitucionais, pelos princípios e se dirigindo às normas ambientais, partindo para as execuções das garantias, temos o artigo $6^{\circ}$ do Código Florestal do Rio Grande do Sul, instituído pela Lei Estadual nº 9.519/1992.

Art. $6^{\circ}$ - As florestas nativas e demais formas de vegetação natural de seu interior são consideradas bens de interesse comum, sendo proibido o corte e a destruição parcial ou total dessas formações sem autorização prévia do órgão florestal competente. (RIO GRANDE DO SUL, 1992)

Esse artigo é chave para compreender as formas de execução das políticas ambientais. É papel das instituições ambientais do Estado proibir cortes e destruição parcial ou total das florestas nativas e vegetação natural de seu interior ao menos que haja autorização prévia através do órgão florestal competente.

Regida pela explorabilidade limitada e condicionada e sua estrutura bifronte (BENJAMIM, 2010), há um aparato estatal que realiza licenciamentos, autorizações e outro aparato para reprimir e fiscalizar crimes ambientais. Assim, para manejar florestas a autorização era feita através do Certificado de Identificação de Floresta Plantada com Espécie Nativa - CIFPEN, fundamentada pelo artigo 9 do Decreto 38355/1998

Art. $9^{\circ}$ - Para fins de exploração futura, de acordo com o Art. 24 da Lei no 9.519 de 21 de janeiro de 1992, e identificar os reflorestamentos implantados com espécies nativas, o proprietário poderá requerer, junto ao Órgão Florestal Estadual, o Certificado de Identificação de Floresta Plantada com Espécie Nativa - CIFPEN. (RIO GRANDE DO SUL, 1998)

É possibilitado ao agricultor plantar e explorar economicamente os frutos das espécies nativas e a madeira das árvores, pois o certificado comprova que foi o agricultor que plantou. Porém, o CIFPEN é um certificado altamente burocratizado e, por isso, pouco utilizado. Além disso esse certificado não contempla os anseios das produções agroflorestais, visto que foram pensados num contexto de produção florestal.

Conectando com o tópico anterior sobre a formação do conceito das Agroflorestas, desde sua origem já se pensavam as Agroflorestas pela supressão da dicotomia entre agricultura e floresta (KING, 1987), no entanto o único certificado disponível pensava pelo prisma da indústria madeireira. Assim como os conceitos científicos passaram por modificações desde sua origem, os dispositivos ambientais também se transformam e são criados para dar conta das demandas existentes. A "ordem do mato" depende dessa malha normativa para vigorar o direito constitucional ao meio ambiente equilibrado, no entanto, as Agroflorestas possuíam espaço inclusivo na legislação estadual mas não encontravam um certificado apto a torná-la parte da ordem. 


\section{FABRICANDO O CERTIFICADO DE AGROFLORESTAS}

A lei vem reconhecendo os Sistemas Agroflorestais como uma forma de exploração sustentável realizada por comunidades tradicionais contemplando-a dentro de atividades de baixo impacto ambiental e pelo interesse social. Através do artigo 10 da Resolução 369/2006 o órgão ambiental competente pode autorizar supressão eventual e de baixo impacto ambiental. As Agroflorestas demandam certos cortes e podas para o real manejo das plantas e árvores, pois arquiteturar intencionalmente as espécies fazem parte do processo agroflorestal de todos os agricultores. Selecionar algumas espécies como prioritárias faz parte dessa forma de produção, e seguindo a risca a legislação, seria um crime ambiental esses cortes sem autorização.

A Resolução 369/2006 possibilita o manejo agroflorestal praticado na pequena propriedade ou posse rural familiar inclusive nas Áreas de Preservação Permanente (APP) e na Reserva Legal (RL) mediante autorização do órgão ambiental

Art. 2. O órgão ambiental competente somente poderá autorizar a intervenção ou supressão de vegetação em APP [...] nos seguintes casos:

II - interesse social:

b) o manejo agroflorestal, ambientalmente sustentável, praticado na pequena propriedade ou posse rural familiar, que não descaracterize a cobertura vegetal nativa, ou impeça sua recuperação, e não prejudique a função ecológica da área; (BRASIL, 2006b)

Nessa mesma seara, o “polêmico" Novo Código Florestal Brasileiro - lei 12.651/2012 também possibilitou a entrada das Agroflorestas através das atividades eventuais ou de baixo impacto ambiental e também como o de interesse social.

Art. $3^{\circ}$ - Para os efeitos desta Lei, entende-se por:

IX - interesse social:

b) a exploração agroflorestal sustentável praticada na pequena propriedade ou posse rural familiar ou por povos e comunidades tradicionais, desde que não descaracterize a cobertura vegetal existente e não prejudique a função ambiental da área;

$\mathrm{X}$ - atividades eventuais ou de baixo impacto ambiental:

h) coleta de produtos não madeireiros para fins de subsistência e produção de mudas, como sementes, castanhas e frutos, respeitada a legislação específica de acesso a recursos genéticos;

i) plantio de espécies nativas produtoras de frutos, sementes, castanhas e outros produtos vegetais, desde que não implique supressão da vegetação existente nem prejudique a função ambiental da área;

j) exploração agroflorestal e manejo florestal sustentável, comunitário e familiar, incluindo a extração de produtos florestais não madeireiros, desde que não descaracterizem a cobertura vegetal nativa existente nem prejudiquem a função ambiental da área; (BRASIL, 2012). 
NORUS - v3, n.4, jul - dez 2015.

Desse modo, os novos regramentos vêm demonstrando um interesse por um espaço jurídico para as Agroflorestas, assim como para manejos sustentáveis, extrativismos e outra formas de florestas serem também cultivadas para comunidades. A ideia aqui é dar um tratamento "diferenciado" para atividades como a das Agroflorestas, possibilitando um espaço de existência que - sob uma autorização do órgão florestal - regulariza agricultores familiares, assentados da reforma agrária, indígenas, quilombolas, ribeirinhos, pescadores artesanais, extrativistas florestais etc.

Antes de 2011 - ano de início do "Projeto de Fortalecimento das Agroflorestas" e das discussões do Subgrupo Manejo da Secretaria de Desenvolvimento Rural no Rio Grande do Sul -, a temática das Agroflorestas não era reconhecida enquanto uma prática que poderia ser considerada como importante para a conservação e para a produção de alimentos para a Secretaria Estadual de Meio Ambiente do Estado: Foi a partir desses espaços políticos que foram fortalecidas a existência de práticas de Agroflorestas no RS e agregado a discussões como extrativismo - açaí (palmeirajuçara) e samambaia-preta, manejo sustentável, agricultura das populações tradicionais e pela união de órgãos de extensão rural, de pesquisa e ambientais é que foram desenvolvidas ideias sobre o manejo em SAF's. As legislações já apontavam nessa direção e os atores propunham a criação de um certificado específico para as Agroflorestas no Rio Grande do Sul.

A Agrofloresta não era reconhecida enquanto manejo florestal pelos técnicos ambientais. No entanto, já haviam procedimentos autorizatórios do Estado que implicavam no plantio, no corte, no manejo, na abertura de picadas de vegetação primária ou secundária, a depender da situação e das demandas de qualquer agricultor, independente de qual seu objetivo. Porém o público que vinha se utilizando dessas ferramentas trabalham em escalas maiores de exploração comercial de espécies madeiráveis ou empreendimentos que deveriam realizar reposições florestais, ou aqueles agricultores que gostariam de realizar descapoeiramento. Ou seja, o objeto desses públicos são as florestas e áreas protegidas em si, e o órgão florestal dá a resposta pensando nas florestas, nas árvores e espécies nativas e no ecossistema do entorno, pensando nos possíveis danos ambientais.

Agricultores familiares que realizam manejos, podas e cortes de árvores nativas junto a cultivos agrícolas sem autorização específica não são alcançados pelas políticas de licenciamento florestal e nem resguardados pelas políticas de agricultura. Os técnicos ambientais sensibilizaram-se na possibilidade de que seus trabalhos não são apenas com as florestas e sim, como nesse caso, com pequenos agricultores interessados em realizar diferentes formas de agricultura e de preservação.

Estão em vigor no Rio Grande do Sul 31 formulários, roteiros e termos de referência para realização de diferentes licenciamentos florestais que compreendem serviços prestados pelo órgão 


\title{
A trama científica e jurídica na construção do certificado de agroflorestas
}

ambiental visando regularizar e fiscalizar diferentes tipos de manejos de espécies florestais nativas e as compensações florestais.

Aqui incluem-se as atividades que o órgão de licenciamento florestal podem fornecer autorização prévia para exploração e reposição florestal. A ideia é propor que são essas as atividades que, retornando ao art. $6^{\circ}$ do Código Florestal, os órgãos governamentais tem a competência de autorizar, certificar, legalizar. No processo de regulamentação da vida e da natureza, oriundos da biopolítica, os licenciamentos florestais são instrumentos em disposição do Estado para "fazer viver" as atividades legimitadas como produtivas e "deixar morrer" outras atividades que não estejam no rol de atividades (FOUCAULT, 1999). Nisso se produz algumas atividades que, por estarem legitimadas pelo licenciamento, são autorizadas a acontecer, ao passo que diversas outras atividades não estão autorizadas - como no caso das Agroflorestas, o uso de frutos e árvores nativas.

$\mathrm{Na}$ trama de atividades autorizadas e não autorizadas - no caso das Agroflorestas por nem serem previstas ou se previstas ainda não regulamentadas - que se forma em torno da verdade produzida pelos ordenamentos jurídicos, Ost nos acrescenta que

\begin{abstract}
Para traçar o limite do permitido e do interdito, instituir responsabilidades, identificar os interessados, determinar campos de aplicação de regras no tempo e no espaço, o direito tem o costume de se servir de definições com contornos nítidos, critérios estáveis, fronteiras intangíveis. A ecologia reclama conceitos englobantes e condições evolutivas; o direito responde com critérios fixos e categorias que segmentam o real. A ecologia fala em termos de ecossistema e de biosfera, o direito responde em termos de limites e de fronteiras; uma desenvolve o tempo longo, por vezes extremamente longo, dos seus ciclos naturais, o outro impõe o ritmo curto das previsões humanas. (OST, 1995, p. 111).
\end{abstract}

Sob a perspectiva de que se está buscando a proteção ambiental e que se deseja manter uma sociedade com equilíbrio ecológico, as ações do direito acabam buscando em formalidades (certificados, autorizações) segmentar o real para defender a multiplicidade e a biodiversidade. Porém o caráter limitante da objetividade pertinente à formação de regras sobrepõe tempos e espaços, multiplicidades e diferentes cultivos e ecossistemas. Nesse aparente "desencaixe" entre o direito e a ecologia é que reside a "falta de coerência", "excesso de burocracia", "peso da lei sobre o agricultor", que se revela claramente para os agricultores agroflorestais.

A partir de encontros, de reuniões e da demanda apresentada para a Secretaria de Meio Ambiente no I Seminário de Agroflorestas do Rio Grande do Sul, foi construído um certificado de Agroflorestas. O documento é o nro. 26 da lista dos licenciamentos florestais: Formulário para requerer certificação de agroflorestas. Os critérios para requerer esse certificado e as condições são

1. Estar devidamente registrado no CAR - Cadastro Ambiental Rural - e em dia com suas obrigações ambientais quando o mesmo estiver em operação; 
2. O registro da(s) área(s) de implantação da Agrofloresta deverá ser requerido no ano dos manejos e antes de seu início;

3. Enquadra-se no requisito legal disposto no art. $3^{\circ}$ da lei 11.326 de 24 de julho de 2006 possuir área de até 4 módulos fiscais, utilizar predominantemente mão-de-obra familiar, ter percentual mínimo da renda familiar originário de sua propriedade ou empreendimento rural e morar na zona rural;

4. Realizar os manejos de vegetação na propriedade licenciada através de boas práticas agronômicas, visando a recuperação da biodiversidade, sem uso de agrotóxicos e estar com sua propriedade regularizada ambientalmente;

5. Priorizar áreas degradadas ou de lavouras e potreiros em desuso ou cuja vegetação seja secundária em estágio inicial de regeneração ou vegetação esparsa cobrindo pouco solo com características degradadas.

Através de entrevistas realizadas com os técnicos ambientais responsáveis pela produção do certificado, constatei a intenção de promover uma política inovadora com o foco em superar o ferramental burocrático existente. Há o reconhecimento pelos técnicos ambientais de que atualmente os pequenos agricultores encontram-se prejudicados por não haver um certificado que contemple seus anseios e que podas, manejos em árvores nativas devam passar pelo crivo ambiental.

\begin{abstract}
A gente quer justamente dar um passo a mais, pra termos uma ferramenta. Notamos que os produtores rurais tem dificuldade até financeira, ele sabe que tem uma área degradada, que ele sabe que tem um passivo ambiental, sabe que de alguma forma ele vai ter que fazer e agora tem o CAR e ai é condição sine qua non como se diz, então ele vai ser obrigado [a recuperar áreas degradadas]. Então justamente nos vimos uma possibilidade de dar uma ferramenta pro produtor. Vai recuperar a área e também pra complementar o sustento ou parte dele, ele não vai perder em área produtiva. Nossa ideia é dar uma alternativa econômica para o produtor a ponto de que ele pudesse recuperar área, aumentar biodiversidade daquela floresta que estava faltando ali e ao mesmo tempo um beneficio social, socioeconômico pra ele.
\end{abstract}

Com a ideia de fomentar uma estratégia de recuperação de áreas degradadas pela ação do homem, o anúncio pelos técnicos é o de que as Agroflorestas podem ser um caminho de recuperação através do uso da propriedade rural com mais eficiência. Abrir a possibilidade na legislação para recuperação de áreas degradadas através das Agroflorestas poderiam a longo prazo recriar matrizes florestais e também dar uma outra resposta a uma cultura de punição.

\footnotetext{
Inclusive no inicio do nosso trabalho a gente tinha a ideia de que seria feito um licenciamento por espécie, licença especifica pro manejo do butiá, no inicio a gente pensava assim. Ao longo do tempo a gente percebeu que isso não seria viável, que não daria como fazer uma coisa espécie por espécie, primeiro por que falta critério cientifico para gente poder se basear nisso, pra tomar uma decisão e criar um sistema de licenciamento, e ai vimos que o ideal seria trabalhar com algo mais amplo, e não fazer por espécie e sim fazer por área da propriedade e por técnica de manejo. Ai estaria a nossa novidade.
}

A novidade que orienta aqui o pensamento sobre certificação deu-se no fato de que algumas tentativas de "certificar por espécies" remonta a ideia de extrativismo como atividade principal. Se 


\title{
A trama científica e jurídica na construção do certificado de agroflorestas
}

o agricultor quisesse, por exemplo, manejar, comercializar, beneficiar a palmeira-juçara e seus frutos, ele estaria certificado apenas quanto a palmeira-juçara. Como já apresentado, as Agroflorestas expandem o cultivo de apenas uma espécie para pensar nas diferentes práticas e em que o agricultor não só extrai da natureza, mas sim planta, cultiva, corta, "conduz" o mato e se alimenta, comercializa, beneficia várias espécies nativas ao mesmo tempo.

A ideia então de "expandir" o certificado foi aproveitada, tendo em vista que certificar áreas específicas de certas espécies tenderia a monocultivar dada espécie nativa, fato que não intensificaria o fomento de matrizes florestais. A aposta na Agrofloresta como algo mais amplo pela sua biodiversidade também ajuda no processo de sua ressemantização. Essa aposta não visa que qualquer Sistema Agroflorestal seja legalizado, e sim aqueles que se pautem pela biodiversidade. A sofisticação da estratégia de certificação em Agroflorestas ao reconhecer que as práticas agroflorestais devem ser também práticas sustentáveis, assim como algumas práticas de extrativismo sustentável que já acontecem. O incentivo à práticas sustentáveis, assim como na evolução do conceito de Agroflorestas, "restringe" práticas para aquelas em direção a agroecologia.

A certificação de Agroflorestas foi possibilitada aproveitando a ideia de pousio e regeneração natural de áreas degradadas com a finalidade de que o agricultor tenha direito a cortar lenha, colher frutos a medida que a sucessão natural venha crescendo. Foi nomeado o termo Sistemas Agroflorestais de base ecológica, num certificado que apresenta algumas facilidades e tramites menos burocráticos, com a vantagem de que no certificado tanto as podas, os cortes e os frutos de espécies nativas podem ser feitos todos no mesmo processo.

\begin{abstract}
Notamos que geralmente são coisas que vem casados, produção orgânicas e agroflorestas. Boas diretrizes que são bem restritivas até. A ideia seria que a certificação daquela área, não da propriedade, pode ser mais de uma, dez dentro da propriedade. A gente conseguiria uma certidão pra ele, que é um ato autorizatório do Estado e cumpre e exigência com o art. $6^{\circ}$, não é exatamente um alvará de licenciamento florestal é só uma certidão, ele (o agricultor) não está licenciado, está certificado. Mas lá na certificação a gente colocaria os textos necessários para dizer que ele está regular. Poderia fazer poda, corte de capoeira, roçada, raleio, manejo, o que for preciso pra implementar um SAF. Tudo isso seriam mais de 13 formulários, e cada vez ele teria que vir no órgão pedir em separado.
\end{abstract}

A importância aqui de um paralelo entre Agroecologia e Agrofloresta, apontada por Ospina (2006), onde as fortes diretrizes parecem agradar ao formulador do certificado, funcionando a agroecologia como parâmetro. A redução de trâmites burocráticos no licenciamento também anima a produção do certificado, podendo ser considerada como um fomento às Agroflorestas.

Assim como "restringir" produz valores positivos - a adoção da agroecologia como parâmetro, produz também suas consequências. Os sistemas que já estão consolidados como Agroflorestas biodiversas não seriam certificados pois os técnicos não acompanharam o 
NORUS - v3, n.4, jul - dez 2015.

crescimento da Agrofloresta, mesmo sendo agroecológico. A ação seria lenta para não beneficiar "mal-feitores" e também seriam implementados "sistemas-pilotos" para o inicio das certificações. Agricultores que já realizam há anos Agroflorestas não poderão legalizar suas áreas, apenas aqueles que iniciarão suas práticas 'do zero' tendo em vista que o órgão ambiental deve contabilizar as espécies da propriedade e ter informações suficientes para permitir o corte e o manejo das árvores após terem crescido. As Agroflorestas estão ainda em pleno "laboratório" tendendo a ser ainda mais "cientificizada".

Como a estratégia é de recuperação de áreas devastadas e não apenas de fortalecimento das práticas dos agricultores, o público dessa política para os técnicos são aqueles agricultores que estão devendo áreas de preservação permanente ou de reserva legal, que possuem passivos ambientais. Uma estratégia de mitigação como oportunidade para recuperar áreas junto com a possibilidade de extrair frutos e sob tutela do órgão ambiental cortar e manejar árvores de acordo com o art. $6^{\circ}$ do Código Florestal Estadual.

Entre "expandir" e "restringir" conceitos e atributos para formação do certificado, a malha conceitual do certificado tem o zelo de não beneficiar a quem não merece, correndo o risco de, à contrapelo, beneficiar poucos agricultores - mesmo os agrecológicos. A fábrica de direitos encontra diversos obstáculos (LATOUR, 2010) quando se depara com a multiplicidade do real, tanto o real das práticas quanto a real malha normativa e o aparato burocrático e fiscalizatório disponível para certificar espaços de Agrofloresta. Assim como existe medo dos agricultores perante os órgãos ambientais, existe o receio por parte dos órgãos ambientais de trabalhar com os agricultores, ao lado deles para beneficiá-los. O "pé atrás" parece ser elemento constitutivo dessa relação entre agricultores e técnicos ambientais.

\section{CONSIDERAÇÕES FINAIS}

Neste sentido, as Agroflorestas são uma tentativa de aliar produção de alimentos e preservação ambiental, conforme o próprio termo indica, aliando agricultura à floresta e floresta à agricultura. Na prática indica cultivos agrícolas misturados intencionalmente com espécies florestais (DUBOIS, 2008) formando um sistema agroflorestal que por sua diversidade de espécie tem o potencial de através do manejo tornar-se um sistema produtivo rico e com diferentes espécies e estratos arbóreos.

O fato é que a ação da trama entre ciências - técnicas agroflorestais, agroecológicas, agronômicas, extrativistas; e o direito - técnicas de normatização ambiental; incidem sobre as 


\section{A trama científica e jurídica na construção do certificado de agroflorestas}

práticas de agricultores que em alguma medida buscam em suas práticas conciliar árvores nativas araucária, cedro, canjerana, palmeira-juçara, louro, ervateiras - à cultivos agrícolas - hortaliças, frutas cítricas, bananais, uvas, forrageiras - em diferentes propriedades nos 'quatro cantos' do Rio Grande do Sul, feitas por agricultores de diferentes culturas, etnias, localidades, ecossistemas.

Importa relacionar aqui que o real em sua multiplicidade (DELEUZE, 2011) - as práticas desses agricultores no mundo - estão em jogo e sendo recobertos por estratégias disciplinares das ciências agronômicas e ecológicas como boas práticas agronômicas e ecológicas exigindo uma comunhão de práticas e saberes entre agricultores e técnicos. Por ser uma prática que em tese cultivam-se árvores e espécies nativas, delegam-se a técnicos ambientais a responsabilidade de um parecer normativo que regularize o manejo agroflorestal pois os agricultores encontram-se margeados pelas normativas e certificações atuais.

Nesse sentido, está em jogo a existência de disciplinamento de práticas (FOUCAULT, 1977). As estratégias disciplinares dos especialistas em Agroflorestas com os agricultores que as praticam, tentando mapear limites, bons exemplos e saídas para legitimação dessa prática como uma prática alternativa provinda dos pequenos agricultores e a necessidade de um posterior processo de certificação, produzindo um regime de verdades em torno das Agroflorestas. A disciplina aqui se dá pelo aparato científico capaz de dar nome a um conhecimento submetido a um processo de tradução de práticas específicas de agricultores e um aparato jurídico-normativo que, subsidiado pela ciência, deve disciplinar limites e possibilidades desse conhecimento no plano das práticas. As ciências agronômicas e biológicas constrói o conteúdo sobre as Agroflorestas e o direito a forma, como malha e ferramenta capaz de disciplinar.

A oportunidade aqui a ser vivenciada remonta que, mesmo uma política de prática de agricultura alternativa passa pelo processo de construção de "politicas de verdade" (FOUCAULT, 1997). Um processo que guarda consigo uma positividade - prática agroecológica, biodiversa enfrenta também suas disputas, suas nuances e suas negociações para poderem estar dentro da normativa estatal.

As Agroflorestas emergem como um conhecimento e necessita das estratégias de disciplinamento, porém a multiplicidade das práticas dos agricultores escapa às padronizações conceituais. Quando os técnicos se debatem em torno de que "uma Agrofloresta nunca é igual a outra", a possibilidade de contemplar a multiplicidade das práticas se choca com a linearidade do conceito e justamente por escapar do controle, da precisão e do dimensionamento, e envolverem práticas a serem experienciadas constantemente, as disputas de poder promovem uma relação tensa 
NORUS - v3, n.4, jul - dez 2015.

entre uma realidade que não está no direito mas que o direito tem que buscar caminhos para recobrir.

\section{REFERÊNCIAS BIBLIOGRÁFICAS}

ALEXY, R. Teoria de los derechos fundamentales. Madrid: Centro de Estudios Constitucionales, 1993.

ANJOS, J.C. Foucault e Bourdieu: derivas de um espaço epistêmico. Anos 90: Revista do Programa de Pós-Graduação em História da Universidade Federal do Rio Grande do Sul, Porto Alegre, v. 11, n. 20, p.139-165, jan. 2004.

BENJAMIM, A.H. Parte II - Direito Constitucional Brasileiro: Constitucionalização do Ambiente e Ecologização da Constituição. In: CANOTILHO, J.J.G; LEITE, J.R.M. Direito Constitucional Ambiental Brasileiro. 3. ed. São Paulo: Saraiva, 2010. p. 77-148.

BENE, J.G.; BEAL, H.W.; COTE, A. Trees, food and people: land management in the tropics. Otawwa, Canada: IDRC, 1977.

BENTHAM, J. O Panóptico. 2. ed. Belo Horizonte: Autentica Editora, 2008.

BOBBIO, N. Teoria do Ordenamento Jurídico. 6. ed. Brasilia: Editora Universidade de Brasília. 1995.

BONAVIDES, P. Curso de Direito Constitucional. 5. ed. São Paulo: Malheiros, 1994.

BOURDIEU, P. O Poder Simbólico. Trad. Fernando Tomaz. Rio de Janeiro: Bertrand Brasil, 1989.

BRASIL. Constituição Federal. Constituição da República Federativa do Brasil: promulgada em 5 de outubro de 1988. Brasilia, 1988. Disponível em:

<http://www.planalto.gov.br/ccivil_03/constituicao/constituicao.htm>. Acesso em: 11 maio de 2014.

BRASIL. Resolução no 369, de 29 de fevereiro de 2006. Dispõe sobre os casos excepcionais, de utilidade pública, interesse social ou baixo impacto ambiental, que possibilitam a intervenção ou supressão de vegetação em Área de Preservação Permanente-APP. Brasilia, 2006b. Disponível em: <http://www.mma.gov.br/port/conama/legiabre.cfm?codlegi=489>.

Acesso em: 01 maio 2014.

BRASIL. Lei n. 11.428, de 22 de Dezembro de 2006. Dispõe sobre a utilização e proteção da 
A trama científica e jurídica na construção do certificado de agroflorestas

vegetação nativa do Bioma Mata Atlântica, e dá outras providências. Brasilia, 2006a.

Disponível em: <http://www.planalto.gov.br/ccivil_03/_ato2004-2006/2006/lei/111428.htm>

Acesso em: 14 fev. 2012.

COSTA GOMES, J.C.C.; ROSENSTEIN, S. A geração de conhecimento na transição agroambiental: em defesa da pluralidade epistemológica e metodológica na prática científica. Cadernos de Ciência \& Tecnologia, Brasília, v.17, n.3, p.29-57, set./dez. 2000.

DELEUZE. Foucault. São Paulo: Brasiliense, 2011.

DUBOIS, J.L. Classificação e breve caracterização de SAFs e práticas agroflorestais. In: MAY, P.H.; TROVATTO, C.M.M (Coord.). Manual Agroflorestal para a Mata Atlântica. Brasilia: Ministério do Desenvolvimento Agrário, 2008. Capítulo 1, p 97-126.

FELDMANN, F.J. CAMINO, M.E.M.B. O direito ambiental: da teoria à prática. In: Revista Forense, Rio de Janeiro, v. 317, 1992, p 95-113.

FOUCAULT, M. Verdade e Formas Jurídicas. Rio de Janeiro: NAU Editora, 1997.

FOUCAULT, M. Em defesa da sociedade: curso no College de France (1975-1976). São

Paulo: Martins Fontes, 1999.

GRAZIANO DA SILVA, J. A nova dinâmica da agricultura brasileira. Campinas: IE/UNICAMP, 1996.

KING. K.F.S. The history of agroforestry. in: STEPLER, H.A.; NAIR, P.K.R. Agroforestry:

A decade of development. Nairobi: ICRAF, 1987.

LATOUR, B. The Making of Law: an ethnography of the Conseil d'Etat. Cambrigde: Polity

Press, 2010.

MARTINE, George. A trajetória da modernização agrícola: a quem beneficia?. Lua Nova, São Paulo, n. 23, p. 7-37, Mar. 1991. Disponível em: $<$ http://www.scielo.br/scielo.php?script=sci_arttext\&pid=S010264451991000100003\&lng=en\&nrm=iso>. Acesso em 27 Nov. 2015.

NAIR, P. K.R. An introduction to Agroforestry, Netherlands: Kluwer Academic Publishers, 1973.

OSPINA, A. Agroforestería. Aportes conceptuales, metodologias y prácticos para el estúdio agroflorestal. Editora Asociación del Colectivo de Agroecologia del Suroccidente Colombiano ACASOC: Cali, Colombia, 2006.

OST, F. A Natureza à margem da lei: a ecologia à prova do direito. Lisboa: Instituto Piaget, 1995. 
NORUS - v3, n.4, jul - dez 2015.

RIO GRANDE DO SUL. Decreto no 38.355, de 01 de abril de 1998. Estabelece as normas básicas para o manejo dos recursos florestais nativos do Estado do Rio Grande do Sul de acordo com a legislação vigente. Porto Alegre, 1998. Disponível em: <http://www.legislacao.sefaz.rs.gov.br/Site/Document.aspx? inpKey=98228\&inpCodDispositive;=\&inpDsKeywords=38355>. Acesso em: 01 maio 2014.

RIO GRANDE DO SUL. Secretaria Estadual do Meio Ambiente. Licenciamento Florestal. Porto Alegre, 2014. Disponível em: <http://www.sema.rs.gov.br/>. Acesso em: 4 jul. 2014.

RIO GRANDE DO SUL. Lei n. 9.519, de 21 de janeiro de 1992. Institui o Código Florestal do estado do Rio Grande do Sul e dá outras providências. Porto Alegre, 1992. Disponível em: <http://www.al.rs.gov.br/Legis/M010/M0100099.ASP? Hid_Tipo=TEXTO

SOMARRIBA, C.E. Que es agroforestería? El Chasqui. Boletin Informativo sobre recursos naturales renovables. Costa Rica, n. 24. p. 5-13., 1990. 